\title{
Research on Voluntary Services in China
}

\author{
Yun Han \\ School of Social Work \\ China Youth University for Political Sciences \\ Beijing 100086, China \\ Tel: 86-10-8856-7627_E-mail: misshan1969@sohu.com, hanyun@cyu.edu.cn
}

\begin{abstract}
In recent years, youth voluntary organizations, community voluntary organizations and different kinds of self-organized grass-root voluntary organizations have been developing rapidly in China, voluntary services are being integrated into our life, and volunteerism has become a value accepted by more and more people. In this paper, the present status and problems of China's voluntary services are analyzed, suggestions are presented aiming at development of voluntary services in China and it hopes to trigger more research and thoughts relating to voluntary services.
\end{abstract}

Keywords: Voluntary service, Volunteer, Current status, Management mechanism

\section{Foreword}

The voluntary service is an important way for citizens to participate in social life and also the soul of civil society and civil society organizations. The most important and immediate function of traditional voluntary organizations is to organize charitable activities and social welfare works, and voluntary organizations are playing the role of social service providers in more and more social activities along with development of modern society. Along with progressive development in economy and society in China, more and more citizens participate in social affairs and volunteers are playing a more and more important role during social construction.

\section{Understanding volunteers}

Voluntary services refer to social programs in which doers legally participate in social life, boost social progress and promote human development at their free will and without consideration of money. Former U.N. secretary general Kofi Annan pointed out on IYV 2001 launching ceremony that the core of volunteerism was services, common ideal and the belief to make the world better jointly.

Volunteers, as practitioners of volunteerism, are people who are in possession of volunteerism and could help others and undertake social responsibilities without consideration of salary. Volunteers are free from private interests and legal restrictions and they go into public welfare undertakings owing to morality, belief, conscience, sympathy and responsibility. In different areas such as Chinese Mainland, Hong Kong and Taiwan, volunteers are named differently.

\section{Current status of volunteers in China}

China boasts the tradition of philanthropy for public interests since ancient times. Since the founding of the People's Republic of China, CPC and Chinese government have been boosting the charity activities through advocating "learning from Lei Feng to do good". At the end of 1980's, the first volunteers organization, the community volunteers association of Xinxing Sub-district Office of Heping District, Tianjin, was founded in China. Since 1990's, the Ministry of Civil Affairs, the CYL Central Committee, the Red Cross Society of China, the All China Women's Federation and All-China Federation of Trade Unions have established volunteers organizations in succession. According to preliminary estimate, there are more than 34 millions of volunteers registered in China, and voluntary services are becoming a concern of all social circles owing to its outstanding social benefits.

\subsection{Community volunteers}

Community volunteer organizations are subject to civil administration system and are managed by Volunteers Working Committee of China Association of Social Workers. So far, 95\% of community neighborhood committees in China have established volunteer organizations, more than 75,000 community volunteers organizations have been formally registered with more than 16 millions of community volunteers. 
The community volunteer organizations have been developing from bottom to top and vise versa. Since the first volunteer association was founded, it generated a huge social effect and was generalized to the whole country by the Ministry of Civil Affairs soon on a national community services experience exchange conference. In April, 1994, the Ministry of Civil Affairs and China Association of Social Workers issued the Notice on Further Developing Community Service Volunteer Activities. In October, 2005, 8 units, including Ministry of Civil Affairs and All-China Federation of Trade Unions issued the Opinions on Promoting Community Voluntary Services. In February, 2006, 12 ministries and commissions, including Ministry of Civil Affairs, Organization Department of the CPC Central Committee and Publicity Department of CPC Central Committee, jointly issued the Opinions on Extensively Developing Voluntary Services at Rural Areas. In April, 2006, the State Council released the Opinions on Reinforcing and Improving Community Services (Guo Fa 2006 No. 14), summarizing the good practice of community voluntary services in recent years and presenting the primary missions hereafter.

The community voluntary services relate to social assistance, special care, helping disabled people and the old, reemployment, community security maintenance, science dissemination and cultural and ideological progress, especially helping the masses in real trouble. For instance, more timely medical services have been provided to more than 70,000 senior citizens, meal delivery service or partnership service to more than 4,000 senior citizens, call bells installed for more than 2,000 old people who live alone and nursing homes established for more than 2,000 lonely seniors through community services in Shanghai. Many community volunteer organizations have established rules and regulations and presented specific requirements for volunteers. For instance, the bylaw of the community service volunteer association of Heping District, Tianjin requires that members should provide services to communities twice at least per month free of charge and would withdraw from the association if one fails to perform voluntary services for three months continuously without special reasons.

\subsection{Youth volunteers}

At the end of 1993, the CYL Central Committee launched the Youth Volunteers Movement (YVM) and founded Chinese Youth Volunteers Association. Up to now, 150 millions (men times) of youths have been motivated to provide more than 5.5 billion hours of voluntary services on poverty alleviation and development, community construction, environmental protection, large-scale competitions, rescue and relief works, overseas services, etc. More than 17 millions of volunteers have been registered, the number of community youth volunteer service stations (bases) is more than 89,000 and more than 2.5 million pairs of mutual-aid teams have been formed. A youth voluntary service system comprising of Chinese Volunteers Association, 35 provincial youth volunteers associations, and associations in more than two thirds of cities and some counties has been formed.

As to organization of large-scale projects, Chinese Youth Volunteers Association could encourage local youth leagues to launch activities, and the activities organized by youth volunteers give priority to projects that are supported by the country, undertaken by communist youth leagues, managed by project teams and operated by the society. The works of youth volunteers cover a wide range and relate to poverty alleviation and development, community construction, environmental protection, large-scale activities, rescue and disaster relief, oversea services, etc. For instance, in June, 2003, the CYL Central Committee, the Ministry of Education, the Ministry of Finance and the Ministry of Personnel jointly implemented the plan for college graduates to offer volunteer services in the western region, and by 2006, more than 40,000 college graduates had been sent to villages and towns of more than 300 poor counties in the west to offer voluntary services for 1-2 years, covering such fields as education, sanitation, agriculture, youth center construction and management, rural remote education, rural culture development, grass-root people's courts, grass-root procuratorates, grass-root legal aid and rural finance development. In the youth volunteers poverty alleviation relay that was experimented in 1996 and implemented in 1998, 16,000 college-bred urban youths have been sent to more than 200 poor counties in the Midwest to offer voluntary services for half a year to two years, covering such fields as elementary education, medical care, agricultural skill generalization, etc, and two working modes, namely developed areas help underdeveloped areas within the same province and the eastern areas help western areas, have been formed. From 2002, the youth volunteer overseas service plan was launched, and excellent youth volunteers are designated to provide voluntary services in some developing countries that have friendly relations with China (Laos for instance) for half to one year and this generates sound international influence.

\subsection{China's Red Cross volunteers}

Voluntary service is one of the seven basic principles of the International Red Cross and Red Crescent Movement. The Red Cross Society of China founded a Volunteers Working Committee in 2005, each provincial Red Cross society has also set up a volunteers working committee and each Red Cross society below county level has set up a volunteers guiding center, activity station or service center. At the present time, the Red Cross Society of China is in possession of 568,000 volunteers, which is a key force for providing humanitarian services.

The Red Cross Society of China thinks much of reinforcing the management of volunteers by registering volunteers and issuing volunteer service certificates. The Red Cross volunteers are required to wear the service certificates when 
providing voluntary services and their service condition would be registered by each working committee, guiding center or service station. Training of volunteers on voluntary service principles, knowledge and associated skills is also emphasized.

The Red Cross volunteers in China mainly provide assistance to the wounded and sick and other sufferers in natural calamities and disruptive events. During works, the Red Cross volunteers give full play to their specific advantages in each field and play an important role in many links of disaster relief, such as disaster condition report, relief material arrangement and distribution, medical rescue, post-disaster epidemic prevention, raising money for victims of disasters, training of masses on primary rescue, publicity on disaster prevention and reduction as well as publicity on blood donation without payment.

\subsection{Chinese women volunteers}

In 2001, All China Women's Federation issued the Opinions on Developing Women Volunteers Groups, requiring women's' federations at all levels to give full play to their advantages to call on women of all nationalities and all walks of life to join the group of volunteers. Community services are emphasized in urban areas and priority is given to helping women increase revenues in rural districts, and it requires paying special attention to laid-off workers, extremely poor families and elderly women. Various service activities are organized regularly or not through to-door service, on-the-spot consultation, training, group aid and bringing science and technology to the countryside.

Despite the efforts of All China Women's Federation on developing women volunteers, it has not organized nationwide movement and has not counted the quantity of women volunteers in China accurately.

Besides the above volunteers, some governmental agencies and social groups also recruit volunteers aiming at some specific activities. For instance, the Ministry of Commerce dispatch volunteers abroad to offer aid to foreign countries and Beijing Olympic Organizing Committee developed Olympic volunteers and relevant departments developed environmental protection volunteers. Some civil volunteer organizations, such as Friends of Nature and Global Village, have achieved rapid development. In addition, some foreign volunteer organizations have also gained ground in China through cooperation with relevant governmental agencies. For instance, more than 30 foreign NGOs have entered China through China International Centre for Economic and Technical Exchanges and China Association for NGO Cooperation, the quantity of assistance projects is more than 200 in more than 70 countries of more than 20 provinces, municipalities and autonomous regions in China. The projects cover agricultural production, drinking water, income-generating activities, integrated community development, medical treatment and sanitation, poverty alleviation, disaster relief and post- disaster reconstruction, education capability development, training on practical techniques, women-centered projects and south-south exchanges.

The expanding group of volunteers is having a growing influence on economic and social development: first, they promote socialist ideological and ethical progress as well as social harmony; second, they meet diversified demand of people and make up for governmental functions; third, they boost the prosperity of education, science and technology and culture by giving play to the potentials of talents and meeting the public demand for participating in public administration; fourth, some jobs are provided and employment pressure is relieved effectively; fifth, diplomatic relations are improved through further exchanges with overseas NGOs.

\section{Difficulties and problems relating to voluntary services in China}

On the whole, China's voluntary services are flourishing, but there are also many difficulties and problems:

\subsection{Long-term mechanism boosting development of volunteer organizations has not been formed.}

Some organizations develop voluntary services through mass movements, which are formalistic and dampens the passion of some people for participating in voluntary services.

\subsection{There is no unified and standard management.}

Due to lack of unified management, the quantity of volunteer organizations, distribution of volunteers, age structure, their expertise have not been counted accurately and the voluntary service development has not been evaluated in an integrated way. The voluntary services have wandered at low level for a long time and some volunteer organizations have repeated works and even depreciate each other. In addition, the nonstandard internal management of voluntary organizations is still obvious.

\subsection{Development of civilian organizations is restricted.}

China practices the system of dual control over NGOs, namely the establishment of NGOs require examination and approval of both relevant competent departments and registration management organs (civil administration departments). Relevant competent departments are in charge of service guidance and daily supervision, while civil administration departments are mainly in charge of registration management, annual inspection, punishment supervision and establishment of rules and regulations. With such management system, the civilian organizations need to be 
attached or affiliated to certain competent departments before registration, while relevant competent departments worry that they may bear joint responsibilities if such civilian organizations violate rules and regulations, thus they lack the enthusiasm to support such civil organizations.

\subsection{Capital shortage has become a principal deterrent restricting development of voluntary services.}

Supported by legislation, voluntary services abroad have got stable and effective financing channels, but China's voluntary services in the initial stage face financial strain. Many good conceptual designs of voluntary services result in formalism owing to capital shortage and it is difficult to continue standard voluntary services in the long term, which has become the focal point of contradictions.

\subsection{Voluntary services lack judicial guarantee.}

So far, besides some local regulations, there is no comprehensive law and enforcement regulations standardizing voluntary services and the rights and obligations of volunteers are undefined. In particular, as to the rights, many volunteers have few chances of receiving related education, training and work guarantee, and some even can't ensure life safety under special conditions.

\subsection{Low level of social recognition also restricts development of voluntary services.}

Voluntary services are still new in China and the public knows little about volunteers and can't participate in voluntary services effectively.

\section{Thoughts and Suggestions on boosting China's voluntary services}

\subsection{The government should support volunteers through releasing favorable social policies and creating legal environment}

So far, Chinese government has not established a complete set of laws and regulations on developing and improving volunteer works and has not presented a systematic and integrated policy system for volunteer activities and volunteer management, thus volunteers are not accepted, voluntary services can't be supported by the society, and the management of volunteers is not stable and standard, therefore, it is in urgent demand to create a favorable policy and legal environment for volunteers. Presently, the support of Chinese government towards volunteers is reflected in four aspects, namely laws and regulations, departmental policies, organization by laws and support from state leaders and divisional leaders. For instance, volunteers are accepted by more people through volunteer registration system and volunteer practice deposit system. Before bidding for the Olympic Games, Beijing Committee of Communist Youth League and Beijing Municipal Volunteers Association submitted a proposal to Beijing Municipal People's Congress on volunteer legislation. Now, this proposal has been scheduled in the legislation program and the parties concerned are now making investigation and drafting. Shanghai Municipal Civil Affairs Bureau prepared to issue some volunteer stimulation policies as early as 2004 , such as being volunteers would be considered when assessing the moral standard of civil servants; undergraduates may be chosen to be excellent students if they serve as volunteers; and healthy and relatively younger senior citizens could deposit help from others in the future if they serve as volunteers now. In October, 2004, the Commission of Legislative Affairs of Shenzhen Municipal People's Congress discussed Shenzhen SEZ Voluntary Service Regulations (Draft) and was ready to release the first voluntary service law in China for guaranteeing the rights and interests of volunteers fully. On June 4, 2005, the Secretary of CPC Hainan Provincial Committee Wang Xiaofeng and 1200 volunteers took an oath to become the first batch of registered volunteers in Hainan Province and Wang became the first registered volunteer among the secretaries of CPC provincial committees. On May 19 and June 6 of the same year, Nanjing and Chengdu respectively established and promulgated Nanjing Municipal Voluntary Service Regulations and Chengdu Voluntary Service Regulations. All these measures would effectively encourage the sustainable development of voluntary services.

\subsection{Cultivate civic culture, promote the participation consciousness of citizens and enhance citizens' acceptance of volunteers}

In the planned economy, the government undertook all public affairs and people had weak democratic consciousness and participation consciousness. The government often called on people to take an active part in voluntary service (learn from Leifeng and do good) through political or administrative measures and evaluated the moral character of each with his performance. In this case, voluntary service activities can't motivate the spiritual needs of people and often become formalistic and go through the motions. In the 1990's, the government presented the reform objective of "small government and great society" by exiting from social field, which provides adequate space for the establishment of civil society and favorable environment for development of civil culture and enhances people's awareness of voluntary service and participation, especially in such fields as publicity on environmental protection, community construction and democratic election. But transformation of governmental acts needs a long time, civil society has just broken surface, and civic culture, such as civic awareness, civic responsibility, civic self-help and mutual aid, civic dedicated spirit and altruism, civil participation, civic desire, civic interests and civic potentials, needs to be further promoted and 
enhanced. In recent years, along with education of civics and influence of mass media, the public has begun to understand and accept the value and significance of voluntary services, but there are few ways for the people to participate in voluntary services due to lack of integral and comprehensive generalization and cooperation. People tend to regard voluntary service as social activities or social practice of teenagers and are reluctant to take part in. To encourage more people to participate in voluntary services, social education of people should be strengthened, adequate service opportunities should be arranged in order to cultivate people's sense of social responsibility and social morality and awareness of participation and to change the voluntary service to self-conscious behaviors. Undoubtedly, the voluntary activities in China are tainted with the color of organization and movement, where slogans and TV images are emphasized, which is necessary but may result in formalism, so silent volunteers who are ready to devote to others unselfishly need to be cultivated.

\subsection{Establish and improve the management model and operation mechanism of voluntary services}

HR planning and job analysis should be done in order to let each volunteer do his best. Planning should be made before recruitment of volunteers by specifying what types of volunteers are needed, what special skills they have to acquire and the number of each type of volunteers. Formal job descriptions should be compiled for each voluntary post, specifying the task, responsibility, timeline, working mode and required knowledge and skills in order to make each volunteer clear about his/her job. In the meanwhile, scientific and reasonable volunteer application form can be designed, so that applicants could fill in their interests, special skills, the expected work schedule and mode upon recruitment in order to match their interest and skills with the posts and to allocate volunteers to proper posts.

Volunteers should be recruited and screened according to plan, so that they could give fully play to their advantages. When volunteers are recruited, their potential pursuit should be understood, as their motivation could restrict what they can do and what they will do. It is difficult to recruit new volunteers and keep former volunteers if their motivation is not considered when they are assigned to certain posts. When volunteers are screened, it is to choose the optimal people instead of someone in perfect agreement with the qualification, namely those who are qualified for volunteers would be further sequenced, so that the people that best conform to post demand would be accepted.

Training of volunteers should be reinforced to encourage personal growth of volunteers. After training and development, volunteers are expected to be familiar with and answer to organizational missions and objectives, historical achievements and organizational expectation and requirements for them, and through on-the-job training, the specialized knowledge, skills and related laws and polices of volunteers would be improved, or volunteers can be given professional tutors to help them solve problems arising in work. Training, as a main way for experience generalization, can motivate the potentials of volunteers, provide them with requisite skills and knowledge for performing tasks and promote their service ability, enhance their service awareness and improve the service effect. After sound training, volunteers could play their roles more freely and actively.

With an eye to the future of volunteers, diversified works should be provided to volunteers. Volunteers could satisfy their high-level demand through providing voluntary services and organizations should provide them with works that could enrich their individual experience and development chances, for instance, increasing the work complexity and combining associated works to create new works in order to diversify the works of volunteers; enabling volunteers take charge of certain task or project alone in order to enhance the host awareness of volunteers; enabling volunteers to contact customers at different levels in order to enhance their response, independence and sensitivity; expanding the power scope of volunteers to enhance their ability of controlling works by themselves; guaranteeing that volunteers could get feedback from objects of voluntary service or colleges on their works. Through these measures, works of volunteers would be more independent and creative and volunteers could get direct feedback and have their sense of achievement maximized.

A work team refers to a group formed aiming at a special problem, project or task, which requires collaboration and cooperation among all members (collectivism), and the active collaboration and joint efforts of the members could achieve much more than the performance of individuals. As a special team formed by people with high sense of social responsibility, sense of mission, dedication and common objective, each group of volunteers should reinforce team development in order to give play to full potentials of volunteers. Therefore, the nonprofit organizations should cultivate volunteers the unified belief and values and strong sense of belonging and sense of responsibility as masters; encourage volunteers to improve their skills in order to enable them work hard by making use of the unique and complementary skills; cultivate harmonious relations among volunteers and a dense atmosphere of mutual trust; meanwhile, pay attention to the mutual cooperation between volunteers and full-time staff and part-time staff. Through such modes, volunteers may feel the force of cooperation and thus improve work efficiency, give play to their advantages and enjoy works and friendship.

Works of volunteers should be evaluated effectively in order to encourage volunteers to improve themselves continuously. Organizations should recognize, praise and reward the achievements of volunteers in time. Besides annual commendation meeting, dinner party, tea party, sincere thanks, solicitation of suggestions from volunteers, trust of 
volunteers, sending greeting cards upon birthday, consideration of timeline of volunteers, supplying better working equipment and providing honorary titles are all ways of reward, and excellent volunteers may serve as trainers or the good deeds of volunteers could be publicized in various ways. In this way, it shows that organizations think much of volunteers and volunteers would be further encouraged and satisfied. Meanwhile, works of volunteers should also be evaluated in order to guide them to improve works, promote skills and develop further. If certain volunteers fail to meet requirements of organizations, they may be assigned to new posts or accept retraining before being allocated again.

\section{Conclusion}

China is developing towards modernization and market economy, the national power is growing, the society is developing, people's life is being improved, but the rapid development and progress also has an impact on different aspects of the society. People are confronted with more and more worries and doubts in the face of life style transition, different cultural values from mainland and foreign countries, flow of rural population to cities, pressure caused by competition and widening wealth gap, etc. The love and sense of duty represented by volunteerism could bring along care, confidence and support to the changing society and thus create a harmonious social atmosphere. It is the key to push ahead with voluntary services in China to develop and expand volunteerism, improve voluntary service and encourage and care for volunteers. Therefore, we should make in-depth study of volunteerism, voluntary services and volunteers in the abstract, be bold in practice and draw lessons from other countries through reinforcing international exchanges and cooperation.

\section{References}

An, Guoqi. (2002). Voluntary Activities in China. Beijing: Central Party Literature Press.

Calling for Specialized Voluntary Services. [Online] Available: http://www.sh.xinhuanet.com, 2007.10.31.

Chinese Youth volunteers Association. (2006). Technical manual for China Youth Volunteer Overseas Service Plan.

Communist Youth League East China Normal University Committee. Comparison between China and Western Countries on the Mechanism of Youth Volunteer Activities. (2004). Ideological \& Theoretical Education, (7): 35.

Ding, Yuanzhu, \& Jiang, Xunqing. (2001). Research on Voluntary Activities: Classification, Evaluation and Management. Tianjin: Tianjin People's Publishing House.

Ding, Yuanzhu. (2005). Building a Sound and Harmonious Society. Beijing: China Economy Publishing House.

Ding, Yuanzhu. Volunteerism in China. [Online] Available: Website of Beijing International Volunteers Association: www.civa.org.cn

Lester M. Salamon et al. (2002). Global Civil Society--Dimensions of the Nonprofit Sector, (translated by Jia, Xijin et al.). Beijing: Social Science Academic Press.

On the Strategy of Sustainable Development of Voluntary Services. [Online] Available: http://www.volunteers.org.cn/Article, 2007.10.25.

Tan, Jianguang. (2004). Globalization and Development of Youth Voluntary Services in China. Journal of China Youth University for Political Sciences, (3): 19.

Tan, Jianguang. (2005). Report on Youth Volunteer Activities in Guangdong Province. Beijing: China Economy Publishing House.

Thomas John Clayton. (2005). Public Participation in Public Decisions: New Skills and Strategies for Public Managers, (translated by SUN Bo-ying et al.). Beijing: China Renmin University Press. 